\section{DO IT YOURSELF}

\section{Cultura y tecnología}

\section{Juan Ignacio Gallego Pérez}

\section{Profesor ayudante}

Dpto. Periodismo y Comunicación Audiovisual. Universidad Carlos III de Madrid. Facultad de Humanidades, Comunicación y Documentación. Edificio Ortega y Gasset. Despacho 17.2.28. C/ Madrid 133. 28903 Getafe (Madrid) Email: juanignacio.gallego@uc3m.es

\section{Resumen}

Surgido de la cultura underground, el Do It Your self (DIY) o Hazlo tu mismo se convirtió en una forma de creación y distribución cultural que tuvo su mayor repercusión en los albores del movimiento punk, convirtiéndose a partir de ese momento en una alternativa a la creación mainstream. Producción, promoción, sellos, radios libres, fanzines, festivales... no dependen de los grandes sellos y sí del buen hacer de los creadores que en muchos casos acababan asimilados por el gran mercado.

En los tiempos actuales las herramientas digitales han evolucionado y la capacidad de expansión del DIY es mucho mayor y los intermediarios se ven amenazados. Del fanzine al blog, de la radio libre al podcasting, la creación de espacios de promoción en diferentes herramientas, las "nuevas radios", la larga cola, el fenómeno fan, todo esto marca un antes y un después en la nueva cultura digital del DIY.

\section{Palabras clave}

DIY, Música Pop, Blog, Podcasting, subculturas, fans, medios alternativos

Key Words

DIY, Pop Music, Blogs, Podcasting, Subculture, Fans, Alternative Media

\footnotetext{
Abstract

The 'Do it yourself' (DIY) became a new way to create and distribute music in the 70s. Emerged from the underground culture, had a significant impact at the beginning of the punk movement that turned into an alternative to mainstream creation. Production, promotion, record labels, alternative radios, fanzines and festivals depended no more on multinational corporation labels and only on the effort of the artists (in many cases later a ssimilated into the mainstream). Nowadays, digital tools have evolved, and the DIY expansion is greater, but intermediaries feel

threatened by the record industry. From fanzine to blog, from free radios to podcasting, the creation of different promotion spaces with different tools, the "new radios", the 'long tail', the fan phenomena, all these events turned out to be a break-even point in the new DIY digital culture.
} 


\section{Objetivos}

Este artículo busca cubrir los siguientes objetivos.

1. Revisar históricamente el desarrollo del Do It Yourself.

2. Ver su relación con diferentes subculturas musicales.

3. Conocer las posibilidades que tienen los creadores musicales en el nuevo pano- rama digital y ver como esto posibilita una ética DIY.

4. Conocer cómo afecta a otros eslabones de la difusión musical el uso de nuevas herramientas que facilitan la conexión entre grupos y fans y la utilización de los micro-medios (fanzines, radios libres, blogs, podcast) para esta labor.

\section{Metodología}

Para conseguir estos objetivos se ha realizado un repaso de bibliografía relacionada con el DIY para analizar sus orígenes y conocer sus relaciones con movimientos underground. Además se ha analizado diversos medios de expresión DIY en la actualidad y se han completado estos análi- sis con entrevistas a personas relacionadas de una u otra manera con el fenómeno en la actualidad. Parte de estas de estas entrevistas se pueden ver en un video distribuido a través de Internet, disponible en http://blip.tv/file/ 1541486

\section{1. ¿Qué es DIY? Do it! ¡Hazlo!}

Presentar el DIY (Do It Yourself o Hazlo tu mismo) es un tanto complejo porque la propia semántica del concepto lo presenta. Pero sí que es cierto que para entenderlo como concepto cultural hay que echar la vista atrás y conocer los orígenes del concepto y de la ética o cultura del DIY. En el entorno que manejamos se puede presentar como una producción contracultural de origen underground, que hace que cualquier persona pueda producir, distribuir o promocionar un producto saltándose las reglas básicas de la sociedad capitalista. Podemos decir que DIY parte de una actitud de confrontación basada en hacer las cosas por encima de los designios del mercado con un componente importante de autogestión.

Si hablamos de cultura underground Maffi (1975: 13) la identificaba "con una parte de la subcultura juvenil (y no exclusivamente) de los Estados Unidos y, por reflejo, de otros países. Asi pues el underground indicaba aquella 'nueva 
sensibilidad' - y sus productos culturales $y$ sociales- nacida originariamente en los años 50 y convertida en la década sucesiva en 'nueva cultura', 'cultura alternativa' o 'contracultura'”.

La ligazón de underground y DIY es continua a pesar de los intentos de apropiación por parte de la cultura mainstream que en muchos casos han fructificado, convirtiéndose en un importante elemento de diferenciación en el mercado.

Se buscaba abolir la especialización y romper las líneas entre el trabajador y el creador, ligado a que cualquiera pudiera crear independientemente de sus orígenes y formación. El DIY se basa en la 'acción', primero actuar y luego pensar. Esto va tomando forma en los primeros setenta, y hay que relacionarlo con movimientos como el Situacionismo, entre otros, que impulsaron intelectuales como Guy Debord o Vaneigem y que se basaba en la actitud de actuar y crear situaciones fuera del control de las culturas dominantes.

El DIY se desarrolla a diversos niveles culturales llegando incluso a la producción tecnológica asociada a la ética hacker (Lizama, 2004) y a la producción de software libre que es otra de las características del hazlo tu mismo tecnológico. El DIY se convierte, en sus diversas manifestaciones, en una práctica contraría a las culturas dominantes. De esta forma cambian las relaciones sociales, creando un sentimiento comunitario e independiente de la industria que busca cambiar las relaciones mercantiles habituales.

Pero no solo hay que hablar de mercado y de oposición al sistema, también entra en juego el sentimiento de necesitar crear e incluso de necesitar bailar. Impulsos más primarios que también se relacionan con la ética DIY. Como veremos más adelante la cultura de baile generó su propio DIY con las raves subterráneas que se pueden identificar dentro de la productividad cultural de la subcultura juvenil. Relacionando cultura, consumo y producción Willis (Longhurst, 2008: 239) habla de la importancia de los jóvenes que pasan de consumir música e interpretarla, a través de la grabación de cintas, bailando e interpretando sonidos y significados, a desarrollar una producción a partir del desarrollo de este consumo que se aprecia en los llamados Sounds Systems que derivarían en las raves, en la grabación y mezcla casera y auto producida y desembocando de forma natural en la necesidad de componer y tocar en directo.

Tras observar cómo afecta el DIY a nivel industrial e ideológico en los campos del activismo político, la tecnología y la creación, a nivel musical hay que hablar del nivel estético. Primero en la importancia de ésta a la hora de crear una comunidad de fans que participen del placer de seguir un determinado estilo. Segundo, a la hora de formar la identidad, y la importancia que tiene la música para resaltar las diferencias respecto a los demás marcando así una línea 
de autenticidad y de pertenencia a un grupo determinado o subcultura.

El último elemento estético a tener en cuenta es lo que podemos llamar sonido o cultura lo-fi, que toma su nombre de forma simbólica frente al sonido hi-fi de alta calidad. El mero hecho de distribuirte y producirte está por encima de la calidad de la grabación e incluso se convierte en muchos casos en una marca estética que revela la autenticidad de un producto DIY por encima de uno que tenga una mejor calidad de sonido. No obstante, sí antes el sonido lo-fi estaba muy vinculado a este tipo de producción casera, en la actualidad y con la evolución de las herramientas digitales de grabación un grupo puede tener sonido de alta calidad con un buen equipo informático y un par de micrófonos.

Resumiendo, el DIY implica tres estadios en el concepto de hazlo tu mismo: uno ideológico/ político, marcado por una rebelión contra el orden jerárquico establecido, otro industrial, que busca nuevas formas de producción fuera de la cultura de masas, creando redes autónomas de producción y distribución, y otro estético, en la búsqueda del sonido que me interesa como individuo y como grupo subcultural.

\section{DIY, música y subcultura}

Para introducir este epígrafe lo primero que hay que hacer es saber que se entiende por subcultura y su relación con la música. Por subcultura entendemos una cultura grupal que se opone o complementa a la cultura dominante gracias a que comparte unos criterios estéticos, políticos o sexuales o como observaba Hebdige en los 70, gracias a que comparten un determinado estilo con una significación especifica (Hebdige, 2004). Si con esta definición de subcultura el objetivo de los grupos o "tribus" era marcar de forma clara la diferencia con la cultura hegemónica en la actualidad Thornton evidencia que lo que buscan subculturas en el nuevo siglo es distinguirse estilísticamente convirtiéndose en grupos de consumo sumamente interesantes. De esta manera nos encontramos con un "capital subcultural" que ayuda a las industrias culturales a fragmentar el mercado ofreciendo un producto diferenciado para los diferentes grupos subculturales (Thornton, 1995), por que más que enfrentadas al mainstream, las subculturas se convierten en un complemento de éste.

La revolución de la cultura juvenil durante los años 50 americanos, que funciono como oposición de la "cultura adulta", desemboco en Elvis Presley y el Rock And Roll. Éste, en un momento dado, fue asimilado por el sistema y dio el paso fundamental de ser utilizado por el mundo de la publicidad para vender productos masivos. A partir de aquí es cuando llega el momento de las subculturas que arrancan con los Teddy 
Boys y se desarrollan durante más de 50 años con los mods, skinheads, punks, indies, hip hop, techno... La música deja de ser un pasatiempo para convertirse en un modo más de comunicar un estilo, una cierta forma de pensar y de enfrentarse a la realidad.

Para ver la relación entre estas subculturas y el DIY nos centraremos en algunas de ellas que lo han llevado a su máxima expresión en sus diversas formas, como puede ser el punk y su rebelión estético-política, la continuación en el post-punk, el indie canónico y la forma en que desarrolla los micro-sellos, la distribución DIY y la cultura de baile con el impulso de eventos subterráneos conocidos como raves. Si trazamos una línea entre estos movimientos encontramos conexiones que permiten seguir las transiciones entre estos estilos.

Hay un elemento común a todos estos movimientos musicales y es que nacidos del underground siempre han tratado de ser asimilados por el sistema, utilizando sus propias características para vender y generar un público objetivo diferenciado. El Punk evoluciono desde unos orígenes radicales hasta que grupos como Clash o Sex Pistols fueron asimilados por las multinacionales. Defendida por muchos como una revolución integrada en el sistema, bien es cierto que la estética punk ha acabado en los escaparates de grandes marcas de ropa, donde se pueden encontrar camisetas de grupos punk y cinturones de pinchos. Si recordamos otros movimientos como la nueva ola madrileña (también identificada como La Movida) o el grunge también empezaron en el underground y fueron finalmente asimiladas por la industria discográfica y por el sistema político. En el caso español como recuerda Fouce (2006: 67) con "una apropiación por parte de los socialistas. Una apropiación que se produce cuando la Movida ha dejado de ser un fenómeno underground y es una etiqueta claramente identificable. El aura de libertad y modernidad que la Movida aportaba era un capital nada desdeñable para un político a la búsqueda de votos”.

Lo que nadie puede negar es que esa ruptura estética supuso un antes y un después para mucha gente que empezó a pensar que otras opciones eran posibles a la hora de crear música y de distribuirla. Citando a Cesar Estabiel que en el prólogo del libro de John Lydon (2007:9) comenta:

"Pero si el significado del punk, alqún momento, tuvo que ver con la ruptura de cualquier estética establecida $y$, lo que es más importante, el cuestionamiento sistemático de uno mismo, desde entonces tomaría un camino y un nombre distinto. John Lydon 10 quío con sus PIL, pero otros músicos espontáneos como Howard Devoto (Buzzcoks y Magazine) o Alex Ferguson (Alternative TV, Psychic TV) también lo entendieron así. Sex Pistols levantaron confusamente los cimientos y los grupos más espabilados desarrollaron aquellas ideas de individualidad y diferenciación. No necesitaban nada ni a nadie para sacar un disco, así la ética del d.i.y. ("do 


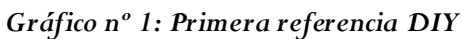

it yourself", hazlo tú mismo: sin medios económicos ni discográficas detrás) se vio posible, después viable y más tarde necesaria.”

A partir del Punk empezaría a gestarse el DIY y a utilizarse la palabra de forma habitual. Los Sex Pistols provocan el despertar de una sensibilidad que desemboca en la que está considerada como primera referencia Do it yourself, hablamos del primer single del grupo de Manchester, Buzzcocks. Publicada el 29 de enero de 1977 bajo el título de Spiral Scratch Ep en su propio sello New Hormones, esta referencia se convierte en el punto de arranque de un movimiento alrededor del que surgieron los primeros sellos considerados indies, sellos como Rough Trade, Factory o Crass que facturaron grupos fuera de los circuitos generales, con formulas de producción, distribución y de relación con los grupos alternativas y lanzaron a algunos de los grupos más importantes de la historia del pop como fueron The Smiths o Joy Division. Factory y Rough Trade, con sus líderes Tony Wilson y Geoff Travis, estaban además fuertemente influenciados a nivel político por el Socialismo y el Situacionismo respectivamente (Craig Strachan, 2003: 54). Además el post- punk genero una serie de redes de distribución, que hoy todavía existen, y que buscaron una democratización de la industria partiendo de planteamientos políticos y haciendo frente en las formas y el fondo a la industria discográfica establecida (Hesmondhalgh,
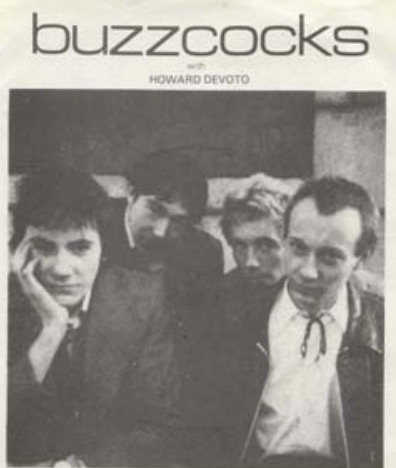

spiral scratch

A partir de aquí y durante los 80 empiezan a surgir sellos y micro-sellos independientes etiquetados como DIY y con intenciones diversas. En Reino Unido aparecen sellos como Postcard o Sarah Records, que facturan lo que podemos etiquetar como indie canónico, basándose en la producción amateur y en la autogestión. En Estados Unidos, ciudades como Olympia (Washington) se convierten en referencia gracias al sello de Calvin Jonson, K Records, que con una actitud no-competitiva y bohemia, que empezó publicando casetes caseros para luego lanzarse al 7" y en la actualidad seguir en activo con una actitud plenamente independiente (Spencer, 2005: 271). Olympia también es la sede de Kill Rock Stars, sello bandera de uno de los movimientos underground más importantes del final de siglo, el de las Riot Grrrl. A partir de este movimiento surge también un festival DIY como es el Ladyfest basado en la autogestión y vinculado al feminismo y al movimiento Queer y que establece redes a nivel mundial llegándose a celebrar dos

1999: 37). 
ediciones en España. El manifiesto del Ladyfest España 2008 define sus principios:

"Cualquier persona puede hacer su propio Ladyfest bajo los criterios del feminismo y el DIY, ayudando a combatir las expresiones sexistas, homófobas, xenófobas y clasistas que están presentes en todos los niveles de la sociedad. El festival no tiene porque ser grande, ni pequeño, ni estrictamente musical: Ladyfest se constituye a partir del colectivo que lo sustenta y le da forma, con sus ideas y sus ilusiones."

Y llegamos a finales de los 80 y principios de los noventa, momento en el que en Manchester comienza a gestionarse la llamada cultura rave, que podemos analizar como una forma de resistencia a través del hedonismo y del escapismo y como un DIYourparty (o hazte tu fiesta). Una forma de revindicar las libertades individuales en el fin del gobierno Thatcher (Nehring, 2007: 8). Citando a Tony Wilson - fundador de Factory Records y del Hacienda Club de Manchester- "las raves son una muestra de fuerza de la comunidad y del colectivo. Una muestra de la fuerza de querer a los demás" (Nehring, 2007: 8). Aquí entraríamos a hablar de la liberación del cuerpo y de la relación entre música y drogas, y la elevación del disc jockey como figura fundamental y como nueva figura de la emergente cultura de clubs.

Hasta aquí hemos visto como evoluciona el DIY en paralelo a algunas subculturas relevantes del final del siglo pasado, de forma que el concepto se aplica a la creación, los eventos o la distribución. A partir de este instante analizamos las relaciones entre DIY, digitalización y música.

\section{DIY, digitalización y música}

Hablar de la industria musical en la actualidad siempre lleva a discursos de queja por el descenso de las ventas, por el cambio galopante del modelo de negocio al que la vieja industria no ha sabido adaptarse. La digitalización de la cultura con la disponibilidad en unos y ceros de gran cantidad de productos culturales ha cambiado las formas de acceso en los últimos años, dando lugar a un nuevo mercado marcado por la eliminación de intermediarios y por la normalización de la autogestión. Si antes cualquier grupo o cantante debía pasar por una discográfica para gestionar su carrera, en la actualidad existen herramientas que cambian considerablemente esta relación entre artistas e industria. En estas relaciones se podría hablar de democratización pero parece más acertado hablar de una popularización de la autogestión.

Empezamos hablando de producción, un ámbito en el que hemos presenciado grandes cambios de unos años a esta parte. Cada vez se hace más popular la producción casera debido al abaratamiento, cuando no gratuidad, de las herramientas. Un 
ordenador que soporte un buen estudio digital es cada vez más barato y nos encontramos con muchos casos de estudios caseros, que dependiendo de la calidad llegan a prestar servicios a otros grupos, por lo que el gran estudio tradicional se hace prescindible. Y además tiene lugar una democratización de la producción no solo por el precio y el fácil acceso a la tecnología sino también por el control que ofrecen estas tecnologías y su fácil manejo (Durant, 1990: 193). Cada vez más artistas se autoproducen en su habitación y luego recurren a estudios de prestigio para realizar la mezcla y el máster final. Casos como el de Wild Honey, una banda madrileña que produce en su cuarto con su estudio casero y se ha ido a mezclar su disco a Nashville con el prestigioso productor Brad Jones. Pero en la habitación no solo se produce, también se remezcla y se realizan creaciones de cut and paste (Yudice, 2007: 27) que luego son utilizadas por los pinchadiscos y aquí hablamos de la cultura colaborativa y del intercambio estético, de la cultura del collage aplicada a la música.

Pero donde se ha producido una verdadera revolución ha sido en la distribución y en la promoción. Si hablamos de distribución musical, hay una gran cantidad de grupos que a través de las licencias libres como Creative Commons o Coloriuris optan por regalar su música, y hablamos de sellos autogestionados como Producciones Doradas o el sello portugués Merzbau Label o grupos como Los Punsetes. También po- demos observar la evolución del DIY hacia micro-sellos que se proponen la venta en $\mathrm{CD}-\mathrm{R}$ haciendo pequeñas tiradas con un diseño muy cuidado como es el caso de Birra y Perdiz o de Moon Palace. Si hablamos de venta directa también es tremendamente interesante IThinkMusic una web que permite la creación de un tienda de venta de música digital para los sellos independientes, llevando a su máxima expresión el concepto de la larga cola (Anderson, 2006), la teoría que despliega que la suma de muchas ventas minoritarias es equiparable a las grandes ventas, y que, sobre todo aquellos distribuidores (iTunes, Amazon, Fnac) que se dedican a un producto digital que no ocupa espacio, no pueden dejar de ingresar lo que producen los artistas minoritarios. Para distribuir la música existe la posibilidad de regalarla a través de una red p2p, Overmundo (iniciativa de distribución de cultura lanzada por el gobierno brasileño libre de publicidad), Myspace o LastFm que es una forma fantástica de conectar con el público objetivo de forma directa. Y este es uno de los elementos que han cambiado de forma más radical, y es que la distancia entre el artista y el fan se reduce, por lo que uno de los elementos clave que ofrecían las grandes discográficas que es la promoción de su música y sus directos la puede realizar directamente el grupo. Para esto además contamos con las redes sociales como Facebook, Myspace, Tuenti o LastFm que interconectan a los fans y permiten la difusión masiva de eventos. 
Un gran ejemplo de las nuevas formas de producción y distribución musical se está produciendo en Brasil con el fenómeno de la tecno brega (Yudice, 2007), que se basa en la creación a partir de la remezcla y una forma de distribución basada en regalar los discos a los vendedores ambulantes, que son los que ganan dinero con esos discos, para luego dedicarse a realizar eventos con los artistas que aparecen en los discos compactos. Como bien dice Ronaldo Lemos en el documental Good Copy Bad Copy, es una nueva forma, completamente innovadora de producir y distribuir cultura, centrándose en el evento para la generación de beneficios para el artista.

Y si hablamos de eventos, llegamos al último eslabón de la cadena, y es que gracias a Internet y las conexiones que facilitan las redes sociales y las herramientas clásicas de la red como el correo electrónico o los sms la autogestión de conciertos es cada vez más fácil. Ya veíamos antes el ejemplo de Ladyfest, pero está claro que cada vez es más fácil poner en contacto a artistas y salas, o como ocurre en el caso de Live In The Living ponen en contacto a gente que ofrece su casa para realizar un concierto y a los grupos y artistas que desean hacer un show en un recinto poco habitual y más intimo. Otro ejemplo es el de Todd $\mathrm{Pa}$ trick, más conocido como Todd P. que organiza conciertos en lugares inverosímiles como parkings, azoteas, galerías y todo con una cultura Do It Yourself que le lleva a contactar con los grupos y difundir posteriormente las fechas a través de un mailing masivo, su myspace o su propia página web (www.toddpnyc.com).

\section{Micro Medios y DIY}

Hemos visto la evolución del hazlo tu mismo en diversos escenarios de la industria musical. Pero hay un elemento que históricamente ha sido clave a la hora de entender el DIY y su evolución en la sociedad del conocimiento. $\mathrm{Y}$ es que este movimiento siempre ha estado tremendamente vinculado a la radio como micro-medio o medio alternativo (radios libres, universitarias, comunitarias, piratas) y al mundo del fanzine como publicación no comercial, de pequeña circulación que es producida y distribuida por sus propios creadores (Spencer, 2007: 13).

Los micro-medios $^{3}$ han sufrido una importante evolución y se puede decir que la digitalización ha traído consigo herramientas que han facilitado la distribución de contenidos en todos los eslabones de la cadena y en diferentes formatos audiovisuales. Podríamos equiparar diferentes formatos clásicos a nuevos formatos que surgen de la red. Como reflejo del fanzine estaría el blog, para reflejar las radios libres tendríamos el podcasting y para los videofanzi- 
nes, la posibilidad de utilizar diferentes portales (youtube, blip, vimeo...) como distribuidores de contenidos. Todos tienen en común unas ventajas fundamentales respecto a los que hemos dado por nombrar como predecesores y es la posibilidad de conseguir una gran difusión a nivel mundial y de conseguir una interacción por parte de los usuarios.

Hablemos de los fanzines y de su evolución. Los inicios están vinculados a la Ciencia Ficción y a unos fanáticos que durante los años 20 del siglo pasado desarrollan los primeros fanzines dedicados al mundo scifi, más adelante veremos como este tipo de publicaciones han estado vinculadas a movimientos underground $\mathrm{y}$ a temas muy concretos como la música, el comic, la literatura de género, el arte, el cine o la acción política. Otros que adoptaron el fanzine fueron los beatniks (Spencer, 2005) o los punks que utilizaron el arte del collage y la fotocopia para llevar al fanzine a su máxima expresión. En España, nos encontramos La Liviandad del Imperdible que en 1977 teorizaba sobre punk y futurismo entre otras labores- y que concentro a El Zurdo, Enrique Sierra y Alaska tres de los miembros del grupo seminal de La Movida, Kaka de Luxe (Fouce, 2006). El fin de siglo es abundante en movimientos contraculturales que utilizan el fanzine, desde el hip-hop al movimiento Queer, pasando por el movimiento Indie en España nos encontramos con un gran número de publicaciones. Muchos de estos productores de fanzi- nes acaban convirtiéndose en editores de ezines o como autores de blogs que les conectan con sus iguales. Y es que cuando hablamos de las motivaciones de un fanzinero para destinar su tiempo a una actividad que no le reporta beneficios económicos, lo primero que pretende es identificarse con su comunidad de iguales, con otros fans y a través del fanzine conseguir cierto prestigio en esta comunidad y compartir sus gustos y conocimientos. Otras motivaciones pueden partir del puro aburrimiento, buscando cierta diversión y también evidentemente como hemos visto la posibilidad de realizar una producción contracultural con tintes políticos. Preguntando sobre motivaciones la gente del Fanzine La Escuela Moderna - fanzine en papel, distribuido también a través de su blog- nos contaba:

"Hacer las cosas de manera autosuficiente, con miras a servir a una comunidad concreta y cercana (estamos por la pequeñización de todo) y sin interferencias exteriores ni afán de lucro alguno. Dar nuestra versión de los hechos".

Con la importante difusión que han conseguido los fans gracias a Internet y a sus publicaciones, es normal también que se busque el beneficio personal de conocer gente y promocionarse profesionalmente gracias a los conocimientos que se demuestran en un blog.

Si hablamos de radio podemos retroceder a las radios piratas que pusieron en marcha en ultramar los empresarios ingleses de la 
industria discográfica que no tenían cabida en la BBC o remitirnos a un nivel más DIY a las radios libres italianas y españolas. En España destacaron dentro de la transición y en la actualidad continúan buscando un modelo de comunicación alternativo y basado en la autogestión y dando espacio a la comunicación más social, por esto les gusta autodenominarse radios sociales ${ }^{5}$ (ver manifiesto de las radios sociales de la Comunidad de Madrid). Si bien el modelo de las radios sociales es un modelo DIY puro, siempre hay que contar con un posible cierre debido a la falta de legislación en España alrededor de las llamadas radios culturales, comunitarias o sociales. Ante esto nos encontramos con aplicaciones en Internet que nos permiten saltar la barrera del éter y la posibilidad de emitir mensajes de audio para todo el mundo. Si primero fue el streaming el que permitió la creación de radios caseras, en la actualidad, el podcasting permite la distribución de contenidos de audio bajo suscripción y nos encontramos con multitud de ejemplos de gente que realiza sus programas desde su casa, con total libertad de contenidos. Llama la atención el caso de Olallo Rubio, un mexicano que tras dedicarse a la radio durante muchos años, decidió que en Internet tendría más libertad evitando así la censura de los medios establecidos. Así su podcast está en los 6 millones de descargas y cuenta con patrocinadores. Otros casos de creación DIY a nivel medios sería el de $M i$ Vecina Martier que nos contesta ${ }^{i}$ al porque de su trabajo, con algunas de las razones que hemos esgrimido durante este artículo: difundir lo que me apetece, aprender $y$ darme a conocer.

\section{Conclusiones}

- El Do It Yourself o Hazlo tu mismo nos lo encontramos como elemento de ruptura y revolución desde el primer underground. Su vinculación a todo tipo de movimientos rupturistas y alternativos ha sido constante. En su evolución hemos visto que ha sido asumido en numerosas ocasiones por el mainstream, pero en otras ha continuado con su objetivo de lucha y alternativa a la cultura dominante.

- Los procesos comunicativos que propone el DIY se han basado habitualmente en saltarse a los intermediarios. Estos procesos en la actualidad se hacen más globales y plurales gracias a Internet. En algunos casos nos permiten llegar a un gran público utilizando herramientas que nos encontramos en la Red. Pero no hay que llevarse a engaños, pese a las herramientas - que en muchos casos están controladas por grandes multinacionales con el único objetivo de obtener beneficios económicos- sigue siendo tremendamente complicado ir más allá de compartir gustos, aficiones y pasio- 
nes con miembros de una comunidad cercana. Lo que sí es evidente es que nos encontramos con medios que nos permite trabajar de forma común e intentar llegar a ese gran público saltándonos a los intermediarios.

- La cultura de la colaboración y de la creación de contenidos a través de la Red está muy asumida por las nuevas generaciones, cambiando sus formas de consumir cultura, y haciendo normal dentro del entorno interactivo la creación y el consumo combinados, lo que Toffler designo como prosumidores. Estas nuevas formas de creación han hecho cambiar las licencias autorales y así han aparecido nuevas formas de licenciar productos como Creative Commons o Coloriuris.

- La relación entre el mainstream y las subculturas musicales se ha basado en una relación basada en la oposición y en la complementariedad, ya que en muchos casos grupos nacidos en el underground han acabado alimentando a las grandes productoras, y se ha generado el llamado Capital Subcultural, que permite sacar partido del gusto de las subculturas. No obstante, en la actualidad el DIY y la digitalización permite que muchos grupos que han seguido este camino se desvinculen de las grandes multinacionales y regresen a la autogestión, consiguiendo un gran desarrollo a nivel internacional.

\section{Referencias}

Anderson, Chris (2007). La economía long tail. De los mercados de masas al triunfo de lo minoritario.

Tendencias Editores. Barcelona.

Craig Strachan, Robert (2003): Tesis Doctoral. DoIt-Yourself: Industry, Ideology, Aesthetics and Micro Independent Record Labels in the UK. University of Liverpool.

Durant, Alan. (1990). A new day for music? Digital technologies in contemporary music-making. Publicado en: Hayward, Philip. Culture, technology and creativity in the late twentieth century. John Libbey. London.

Fouce, H. (2006): El futuro ya está aquí. Velecio Editores. Madrid.

Hebdige, Dick (2004): Subcultura. El significado del estilo. Paidós Comunicación. Barcelona.

Hesmondhalgh, D. (1999): Indie: The Institutional Politics and Aesthetics Of A Popular Music Genere.
Cultural Studies. Volume 13, Number 1, 1 January 1999, pp. 34-61(28).

Kusek, David y Leonhard, Gerd (2005): The future of music. Manifesto for the music revolution. Berklee Press. Boston

Lessig, Lawrence (2005): Free Culture. The nature and future of creativity. Penguin. London.

Lizama, J. (2005): Phreakers y Hackers: la apropiación social de la tecnología una nueva matriz cultural. Disponible en:

http: / / www.cibersociedad.net/ congres2004/grups/ fitxa com_publica2 .php.idioma $=$ es\&id $=600 \&$ grup $=3$.

Longhurst, Brian (2007): Popular Music And Society. Polity Press. Cambridge.

Lydon, John (2007): Rotten: no Irish, no Blacks, no Dogs. Acuarela Libros \& Antonio Machado. Madrid. 
Maffi, Mario (1975): La cultura underground. Anagrama. Barcelona.

McKay, George (Ed.) (1998): DIY Culture. Party \& Protest in Nineties Britain. Verso. London.

Nehring, Neil (2007): “Everyone's Given Up and Just Want to Go Dancing": From Punk to Rave in the Thatcher Era. Popular Music And Society: Bowling Green: Feb 2007. Vol. 30, Iss. 1.

Reynolds, Simon (2005): Rip it up and start again. Faber. London.

Spencer, Amy (2005): D.I.Y. The rise of lo-fi culture. Marion Boyards. London.

Tapscott D., Williams A. (2007): Wikinomics. La nueva economía de las multitudes inteligentes.

Paidós. Barcelona.

Thornton, Sarah (1995): Club Cultures: Music, Media and Subcultural Capital. Polity Press. Cambridge.

Yudice, George (2007): Nuevas tecnologías, música y experiencia. Gedisa. Barcelona.

New York Times. Off The Beaten Beat. 11-3-2007 http:/ / www.nytimes.com/2007/05/11/arts/music/11r ock.html? $\mathrm{r}=1 \& \mathrm{ei}=5087 \& \mathrm{en}=7026 \mathrm{ae} 535 \mathrm{e} 192 \mathrm{bcd} \& \mathrm{ex}=1$ $\underline{183089600 \text { \&pagewanted }=\text { all }}$

Público. Amor y pegamento. 28-12-2007.

Wired. David Byrne's Survival Strategies for Emerging Artist- and Megastars by David Byrne.

http:/ / www.wired.com/ entertainment/music/magazine /16-01/ff byrne?currentPage $=$ all
Good Copy Bad Copy (2007). Dirigido por Andreas Johnse, Ralf Chrsitensen, Henrik Moltke. Disponible en http: / / www.goodcopybadcopy.net

Birra y perdiz- http: / /www.birrayperdiz.com/

Creative Commons-

http: / / es.creativecommons.org/

Coloriuris- http: / / www.coloriuris.net/

La Escuela Moderna-

http: / / www. laescuelamoderna.blogspot.com /

I Think Music-http: / / www.ithinkmusic.com/

Kill Rock Stars- http: / / www. killrockstars.com /

K Records- http: / / www. krecs.com/

Merzbau Label- http: / /www. merzbau-label.org

Mi Vecina Martier-

http: / / www.mivecinamartier.com/

Moon Palace- http: / / moonpalacerecords.com/

Overmundo- http: / / www.overmundo.com.br/

Producciones Doradas-

http: / / www produccionesdoradas. com

Los Punsetes- http: / / www. lospunsetes.com/

Wild Honey-

http: / / www.myspace. com/wildhoneysongs

Yoyo Industrias-

http: / / www.myspace.com/yoyoindustrias 
${ }^{1}$ Entrevista por Email - Recibida el 26/11/2008

${ }^{2}$ Publicado en http: //www.patiomaravillas.net/ladyfest/manifiesto-ladyfest-spain-2008

${ }^{3}$ Entendemos por micro-medios, aquellos medios alternativos a los medios mainstream con origen subcultural y do it yourself.

${ }^{4}$ Entrevista por realizada por Email - Recibida el 2/12/2008

${ }^{5}$ http: / / www.urcm.net/spip.php?rubrique1 \#Articulo2

${ }^{6}$ Entrevista por Email - Recibida el 26/11/2008 